\title{
Analisa Pola Temperatur Udara Permukaan di Sumatera Barat Tahun 1980 - 2017
}

\author{
Hanifah Azzaura Musyayyadah*, Mutya Vonnisa \\ Jurusan Fisika Universitas Andalas \\ *ifah.azzaura89@gmail.com
}

\begin{abstract}
ABSTRAK
Temperatur udara permukaan di Sumatera Barat telah diteliti menggunakan data stasiun Badan Meteorologi, Klimatologi, dan Geofisika (BMKG) untuk 11 tahun pengamatan (2007 - 2017) di empat lokasi, yaitu Teluk Bayur (Padang), Minang Kabau (batas kota Padang - Padang Pariaman), Sincincin (Padang Pariaman) dan Padang Panjang. Selain itu digunakan juga data re-analisis dari European Centre for Medium-Range Weather Forecasts Re-Analysis interim model data (ECMWF ERA-Interim) untuk 38 tahun pengamatan $(1980$ - 2017). Osilasi internal temperatur udara permukaan di Sumatera Barat diamati menggunakan transformasi wavelet dengan mother Maxican Hat. Hasil penelitian menunjukkan bahwa temperatur udara permukaan rata - rata di Sumatera Barat meningkat sekitar $0,007^{\circ} \mathrm{C}-0,01^{\circ} \mathrm{C} /$ tahun . Temperatur maksimum harian meningkat sekitar $0,058^{\circ} \mathrm{C}-0,066^{\circ} \mathrm{C} /$ tahun, sedangkan temperature udara minimum harian meningkat sekitar $0,028^{\circ} \mathrm{C}-0,045^{\circ} \mathrm{C} /$ tahun. Periode ulang temperatur udara permukaan di Sumatera Barat yang paling dominan adalah satu tahun, atau biasa disebut osilasi tahunan yang disebabkan oleh monsun. Selain itu, terdapat osilasi 4 dan 8 tahun yang bersesuaian dengan siklus $\mathrm{El}$ Nino Southern Oscillation (ENSO). Dengan demikian dapat dikatakan bahwa temperatur udara permukaan di Sumatera Barat dipengaruhi oleh monsun dan ENSO.

Kata kunci: Temperatur udara permukaan, Sumatera Barat, ERA-Interim, monsun, ENSO
\end{abstract}

\section{ABSTRACT}

Surface air temperature in West Sumatra has been studied using Meteorology, Climatology, and Geophysics Agency (BMKG) 11 years of observation (2007 - 2017) of Teluk Bayur (Padang), Minang Kabau airport (Padang city suburb), Sincincin (Padang Pariaman) and Padang Panjang The result is compared with the European Center for Medium-Range interim model Weather Forecasts Re-Analysis data (ECMWF ERA-Interim) for 38 years (1980 - 2017). The internal oscillation of surface air temperature in West Sumatra were also investigated using a wavelet transformation with Maxican Hat mother. The results showed that the average surface air temperature in West Sumatra increase around $0,007^{\circ} \mathrm{C}-0,01^{\circ} \mathrm{C}$ /year. Maximum daily temperature increased around $0,058{ }^{\circ} \mathrm{C}-0,066^{\circ} \mathrm{C}$ /year, and minimum daily temperature also showed an increase around $0,028^{\circ} \mathrm{C}-0,045^{\circ} \mathrm{C}$ /year. The most dominant period of surface air temperature in West Sumatra is one year, or commonly called annual oscillations which is caused by monsoons. In addition, there are 4 and 8 year oscillations that correspond to the ElNino Southern Oscillation (ENSO) cycle. Thus, the surface air temperature in West Sumatra is influenced by Monsoon and ENSO.

Keywords: Surface air temperature, West Sumatra, ERA-Interim, Monsoon, ENSO.

\section{PENDAHULUAN}

Intergovernmental Panel on Climate Change (IPCC) (2007) menyatakan, rata-rata temperatur permukaan global meningkat dengan laju $0,74^{\circ} \mathrm{C} \pm 0,18^{\circ} \mathrm{C}$ selama seratus tahun terakhir. Namun, menurut Hartmann dkk. (2013), pola kenaikan temperatur permukaan ini tidak homogen secara global. Di beberapa daerah pemanasan teramati lebih tinggi akibat beberapa faktor seperti, topografi, jarak laut ke samudera, dan pengaruh pola sirkulasi atmosfer di tiap wilayah yang berbeda. Jones dkk. (2012) melakukan penelitian dalam skala benua dan mengamati bahwa benua utara menghangat sekitar $0,1^{\circ} \mathrm{C}$ selama bertahun-tahun sejak 2001 . Moran-Tejeda dkk. (2016) menilai perubahan temperatur udara di equator menunjukkan pemanasan yang intens di setiap daerah, kecuali di sepanjang wilayah pesisir. Perubahan temperatur udara dalam skala regional pernah diteliti oleh Martinez dkk. (2010) menggunakan data 37 stasiun temperatur di Catalonia. Secara umum peningkatan tren harian maksimum (Tmax) dan tren harian minimum (Tmin) mencapai $0,5^{\circ} \mathrm{C} /$ dekade.

Penelitian dalam skala besar baik yang mencakup seluruh bumi maupun benua menggunakan data dari stasiun meteorologi yang terbatas, sehingga penelitian dalam skala regional sangat diperlukan untuk memberikan gambaran spasial mengenai temperatur yang lebih rinci, seperti yang pernah dilakukan di Peru (Vicente dkk., 2017), Cina (He dkk.,2016), 
dan Kanada (Nalley dkk., 2013). Penelitian dalam skala regional juga sudah dilakukan di Indonesia untuk beberapa wilayah saja seperti yang dilakukan oleh Purwantara (2015) di Jawa tengah dan Daerah Istimewa Yogyakarta yang menunjukkan bahwa terjadi peningkatan temperatur sebesar $0.01^{\circ} \mathrm{C} /$ tahun. Selain itu, Fadholi (2013) juga melakukan penelitian serupa di Pangkal Pinang dan hasilnya menunjukkan bahwa dalam periode tahun 2000 - 2011 rata rata harian naik sebesar $0,0292{ }^{\circ} \mathrm{C} /$ tahun dan temperatur udara minimum naik $0,0365{ }^{\circ} \mathrm{C}$ /tahun. Temperatur udara maksimum mempunyai kecenderungan turun dengan laju penurunan sebesar $0,01095{ }^{\circ} \mathrm{C}$ /tahun.

Penelitian ini akan membandingkan tren temperatur udara permukaan di Sumatera Barat (Sumbar) yang didapat dari stasiun pengukuran dengan data re-analisis. Penelitian mengenai temperatur udara permukaan dapat menggunakan data pengukuran maupun data reanalisis. Data re-analisis merupakan data gabungan observasi yang belum lengkap, sehingga disempurnakan dengan pemodelan. Data ini sering digunakan untuk mewakili keadaan sebenarnya dari atmosfer menurut pengamatan. Hasil perbandingan akan menentukan apakah penelitian mengenai temperatur udara permukaan ini bisa dilanjutkan menggunakan data reanalisis untuk rentang waktu yang lebih panjang dan skala yang lebih luas, mengingat data reanalisis merupakan data pengukuran yang disempurnakan dengan hasil pemodelan. Dengan adanya penelitian ini, kenaikan temperatur udara permukaan di setiap wilayah Sumatera Barat akan dianalisa. Selain itu, osilasi internal temperatur udara permukaan di Sumatera Barat dianalisa menggunakan transformasi wavelet.

\section{METODE}

Penelitian ini menggunakan data temperatur udara yang tersedia di Badan Meteorologi, Klimatologi, dan Geofisika (BMKG) Sumbar sebagai data utama. Terdapat empat stasiun yang dijadikan wilayah pengamatan, yaitu Stasiun Teluk Bayur (Padang), Stasiun Minang Kabau Airport (batas kota Padang - Padang Pariaman), Stasiun Sicincin (Padang Pariaman), dan Stasiun Padang Panjang. Masing-masing stasiun menyediakan data 11 tahun pengamatan (2007 - 2017). Penelitian ini juga menggunakan European Centre for Medium-Range Weather Forecasts (ECMWF) Re-Analysis interim untuk 38 tahun pengamatan $(1980$ - 2017) sebagai data pembanding.

Regresi linear digunakan untuk mengamati tren temperatur rata-rata, temperatur minimum, dan temperatur maksimum. Dengan demikian dapat diperoleh wilayah pengamatan yang mengalami peningkatan temperatur tertinggi dan terendah. Hasil yang didapat dari data pengukuran dan data re-analisis untuk tahun pengamatan yang sama (2007 - 2017) akan dibandingkan untuk menentukan tren temperatur udara permukaan rata - rata di Sumatera Barat selama 38 tahun pengamatan $(1980$ - 2017). Osilasi internal temperatur udara permukaan di Sumatera Barat beserta faktor yang mempengaruhinya juga diamati menggunakan transformasi wavelet dengan mother Mexican Hat.

\section{HASIL DAN DISKUSI}

\subsection{Temperatur Udara Permukaan Rata-rata Sumatera Barat}

Gambar 1 menunjukkan rata - rata temperatur udara permukaan di Sumatera Barat menggunakan data ECMWF ERA-Interim selama 38 tahun pengamatan (1980 - 2017). Temperatur udara permukaan rata - rata di Sumatera Barat bervariasi antara satu daerah dengan daerah lainnya. Secara umum, semakin jauh lokasi suatu daerah dari laut, semakin rendah temperatur udara permukaan di daerah tersebut. Temperatur udara permukaan di bawah $26^{\circ} \mathrm{C}$ teramati di seluruh wilayah Sumatera Barat, kecuali Kabupaten Mentawai dan lautan sekitar yang memiliki temperatur yang lebih tinggi $\left(>26^{\circ} \mathrm{C}\right)$ selama tahun pengamatan.

Perbedaan Temperatur antara darat dan laut di Sumatera Barat secara umum dapat disebabkan oleh dua faktor. Pertama, kalor jenis laut lebih tinggi dibandingkan kalor jenis daratan, sehingga laut lebih lama menyimpan panas dibandingkan daratan. Oleh sebab itu, temperatur rata-rata laut lebih tinggi dibandingkan daratan. Kedua, daratan memiliki topografi yang lebih tinggi dibandingkan dengan lautan. Di Sumatera Barat terdapat beberapa dataran 
tinggi yang merupakan deretan pegunungan Bukit Barisan (Gambar 2). Semakin tinggi suatu permukaan, maka temperatur udaranya akan semakin rendah.

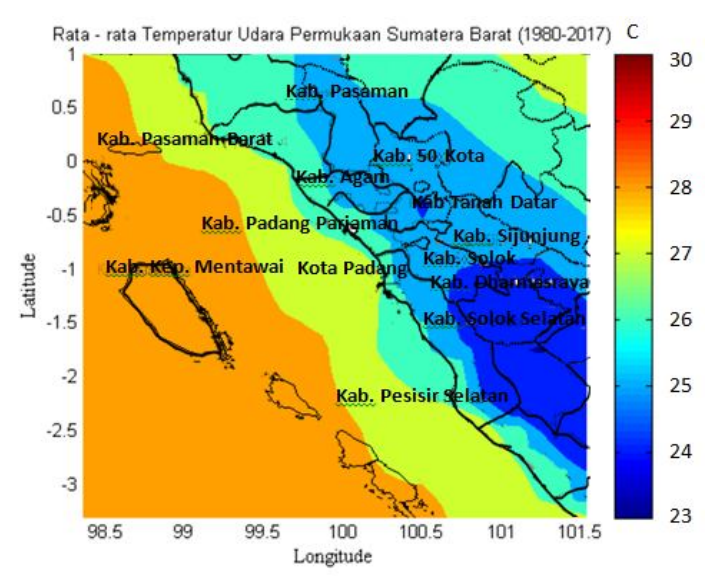

Gambar 1 Temperatur Udara Permukaan Rata-rata Sumatera Barat

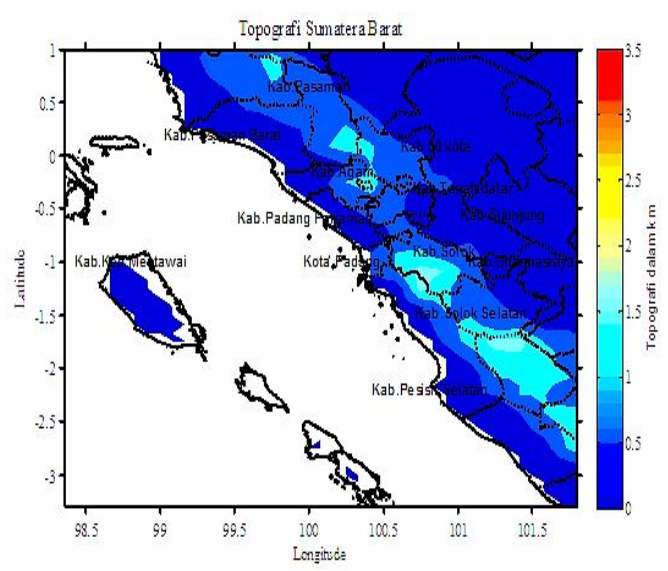

Gambar 2 Topografi Sumatera Barat

\subsection{Tren Temperatur Udara Permukaan Sumatera Barat}

Gambar 3 menunjukkan tren temperatur udara permukaan rata - rata di beberapa wilayah Sumatera Barat yang didapat dari stasiun pengukuran dan data re-analisis ECMWF ERA - Interim untuk sebelas tahun pengamatan $(2007$ - 2017). Secara umum tren temperatur kedua data menunjukkan peningkatan, kecuali data stasiun pengukuran Kota Padang yang dibagi menjadi dua titik stasiun, yaitu Stasiun Teluk Bayur dan Stasiun Minang Kabau Airport di batas Kota Padang - Padang Pariaman. Penurunan temperatur sebesar 0,0032 ${ }^{\circ} \mathrm{C} /$ tahun terjadi di Teluk Bayur, sedangkan di batas Kota Padang - Padang Pariaman temperatur mengalami penurunan sebesar $0,0013^{\circ} \mathrm{C} /$ tahun. Selain itu, pada stasiun Sicincin yang terletak di Kabupaten Padang Pariaman dan Stasiun Padang Panjang di Kota Padang Panjang menunjukkan peningkatan temperatur berturut - turut sebesar $0,0117^{\circ} \mathrm{C} /$ tahun dan $0,0201^{\circ} \mathrm{C} /$ tahun.

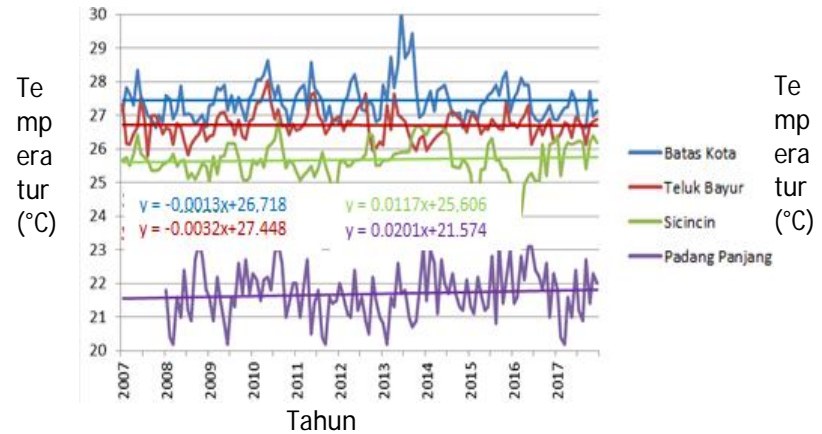

(a)

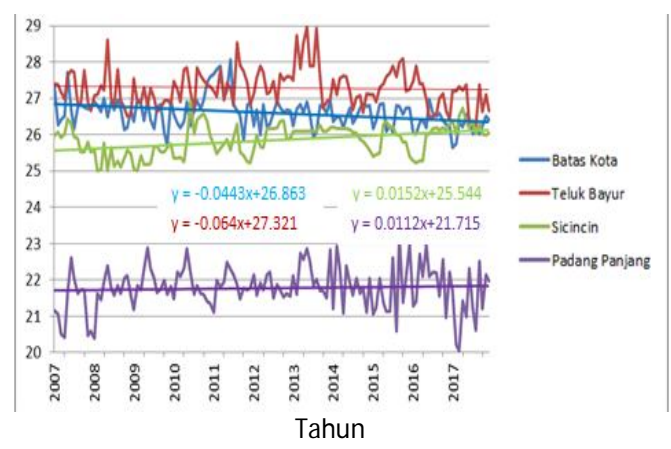

(b)

Gambar 3 Perbandingan tren temperatur udara permukaan Sumatera Barat dari data pengukuran (a) data re-analisis (b) untuk 11 tahun pengamatan (2007 - 2011)

Tren yang sama juga teramati dari data re-analisis, dimana untuk sebelas tahun pengamatan (2007 - 2017) Kota Padang juga menunjukkan penurunan sebesar $0,064^{\circ} \mathrm{C} /$ tahun (Teluk Bayur) dan $0,0443^{\circ} \mathrm{C} /$ tahun (batas kota). Kenaikan temperatur sebesar $0,0152{ }^{\circ} \mathrm{C} /$ tahun teramati di Padang Pariaman dan kenaikan temperatur sebesar 0,0112 ${ }^{\circ} \mathrm{C} /$ tahun di Padang Panjang (Gambar 3b). 


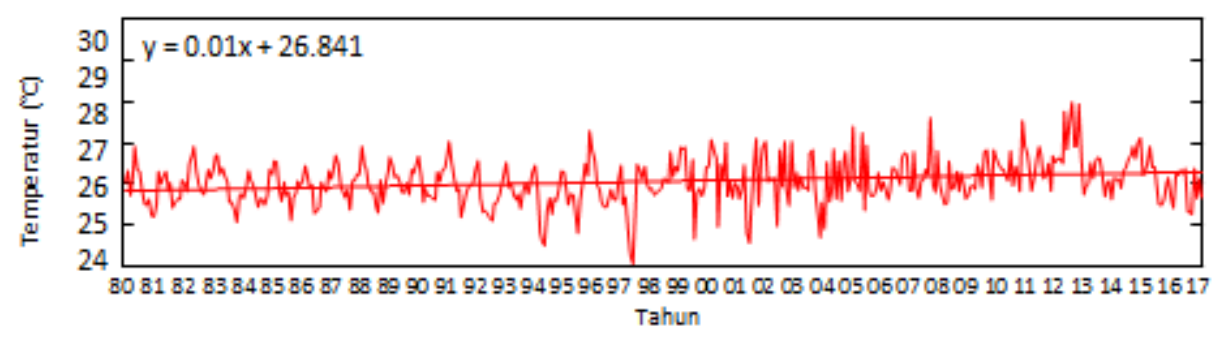

(a)

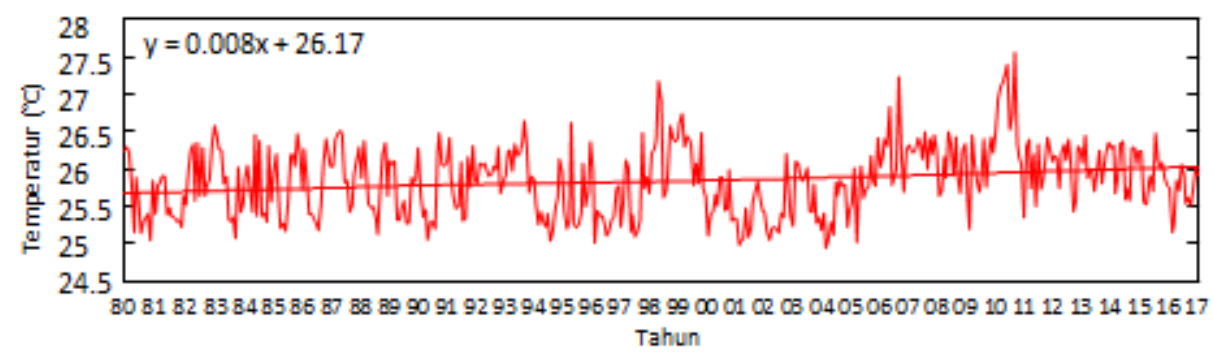

(b)

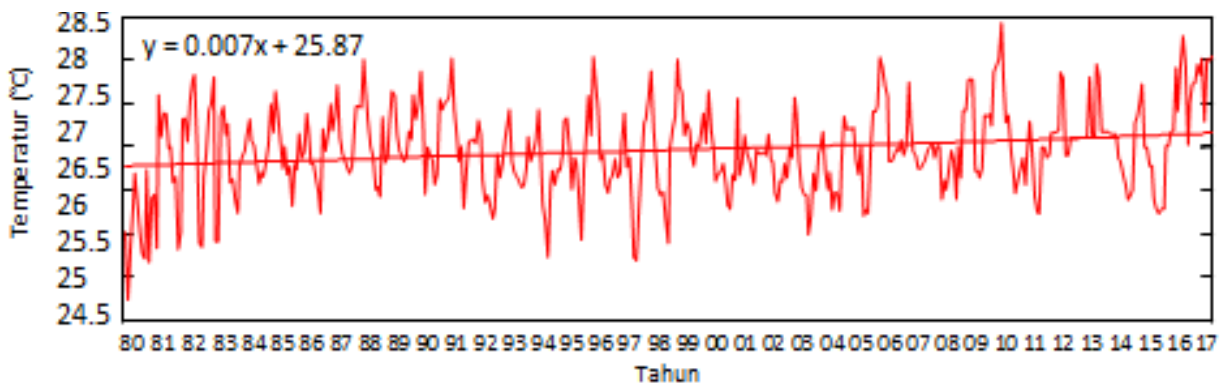

(c)

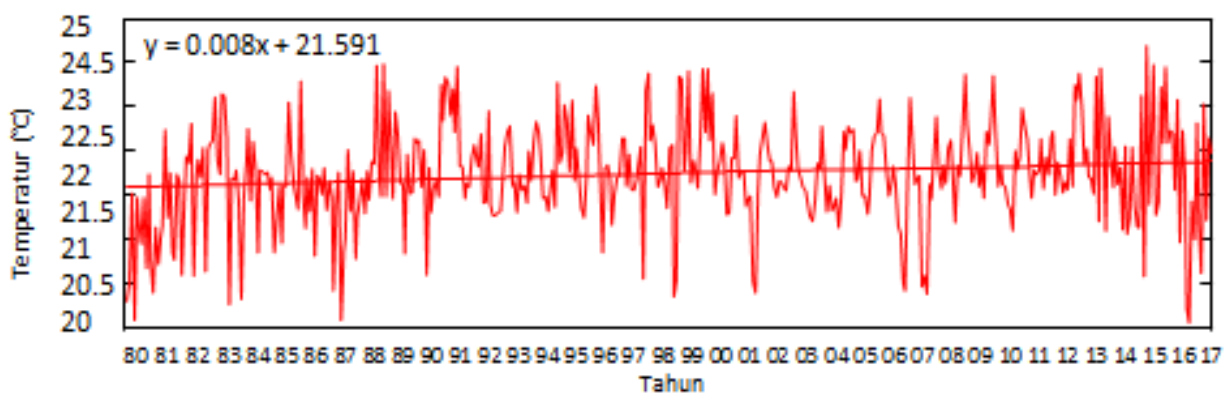

(d)

Gambar 4 Tren temperatur udara permukaan bulanan di Sumatera Barat menggunakan data ERA - Interim untuk 38 tahun pengamatan (1980 - 2017) di wilayah pengamatan (a) Padang (Teluk Bayur), (b) Padang (Batas Kota Padang - Padang Pariaman), (c ) Padang Pariaman, dan (d) Padang Panjang

Dari uraian di atas, diketahui bahwa pola temperatur antara data pengukuran dan reanalisis sama dan hampir saling tumpang tindih untuk tahun pengamatan yang sama. Oleh sebab itu, untuk mengetahui tren temperatur udara permukaan rata - rata di Sumatera Barat digunakan data ERA-Interim seperti yang ditunjukkan oleh Gambar 4. Temperatur udara permukaan rata - rata di Sumatera Barat meningkat dengan laju yang tidak jauh berbeda untuk keempat wilayah pengamatan, yaitu sekitar $0,007-0,01^{\circ} \mathrm{C} /$ tahun. 
Terjadinya kenaikan temperatur udara permukaan rata - rata ini juga diikuti dengan perubahan temperatur udara maksimum dan minimum harian di wilayah pengamatan, yaitu Kota Padang, Padang Pariaman, dan Padang Panjang yang dapat dilihat pada Gambar 5. Peningkatan temperatur udara maksimum dan minimum harian untuk sebelas tahun pengamatan terjadi di seluruh wilayah pengamatan. Temperatur maksimum dan minimum harian di Kota Padang memiliki laju peningkatan sebesar $0,058^{\circ} \mathrm{C} / \operatorname{tahun}$ dan $0,028^{\circ} \mathrm{C} /$ tahun, di Kabupaten Padang Pariaman sebesar $0,066^{\circ} \mathrm{C} /$ tahun dan $0,045^{\circ} \mathrm{C} /$ tahun, dan di Kota Padang Panjang meningkat sebesar $0,063^{\circ} \mathrm{C} /$ tahun dan $0,033{ }^{\circ} \mathrm{C} /$ tahun. Dengan demikian dapat disimpulkan bahwa peningkatan temperatur udara permukaan bukan hanya terjadi secara global namun juga pada lokasi spesifik seperti Kota Padang, Kabupaten Padang Pariaman, dan Kota Padang Panjang.

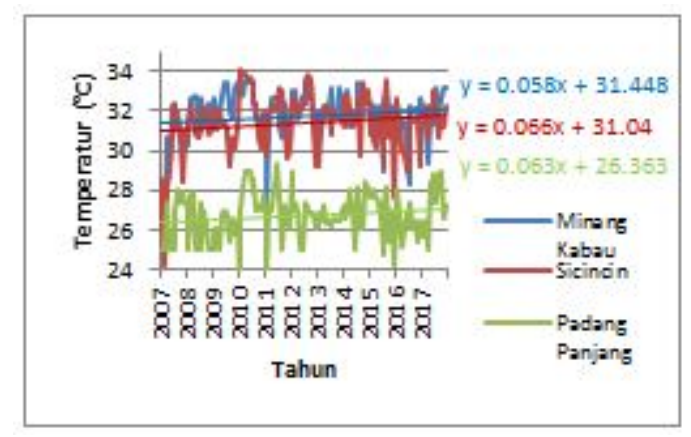

(a)

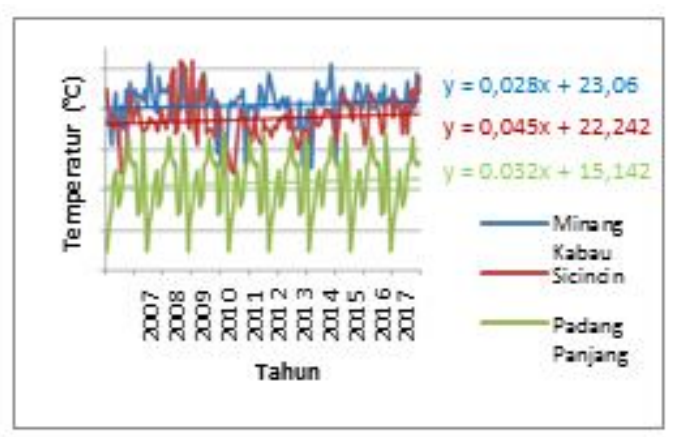

(b)

Gambar 5 Tren temperatur udara maksimum harian (a) dan temperatur udara minimum harian (b) di Sumatera Barat untuk 11 tahun pengamatan (2007 - 2011)

\subsection{Osilasi Internal Temperatur Udara Permukaan di Sumatera Barat}

Osilasi internal temperatur udara permukaan di Sumatera Barat selama 38 tahun (1980 - 2017) ditunjukkan pada Gambar 6 dengan menggunakan transformasi wavelet. Gambar 6a merupakan osilasi temperatur di Sumatera Barat selama 38 tahun (1980-2017). Dari spektrum tersebut terliha periode ulang dominan data temperatur udara permukaan di Sumatera Barat adalah satu tahun, atau disebut osilasi tahunan. Osilasi tahunan ini terjadi akibat angin monsun yang berubah arah sekali setahun (Yuggotomo dan Ihwan, 2014). Selain itu juga terlihat bahwa temperatur udara permukaan di Sumatera Barat juga memiliki siklus 4 dan 8 tahunan yang bersesuaian dengan siklus perulangan ENSO.

Untuk menguji analisis ENSO, time series spektrum wavelet dibandingkan dengan indeks ENSO yang terukur oleh BMKG. Dari data BMKG diketahui bahwa El Nino terjadi pada tahun 1982, 1983, 1987, 1991, 1992, 1993, 1994, 1997, 2004, 2006, 2009, 2010, dan 2012, sedangkan La Nina terjadi pada tahun 1980, 1981, 1983, 1984, 1985, 1988, 1995, 1996, 1998, 1999, 2000, 2005, 2007, 2008, 2010 dan 2011. Jika indeks ENSO dibandingkan dengan hasil yang didapatkan spektrum global wavelet, maka dapat diamati bahwa kedua hasilnya menunjukkan kesesuaian. Dengan demikian, dapat dikatakan bahwa ENSO turut mempengaruhi temperatur udara permukaan di Sumatera Barat.

Gambar $6 \mathrm{~b}$ menunjukkan nilai varian temperatur udara permukaan di Sumatera Barat. Pada tahun 2004, nilai temperatur udara permukaan di Sumatera Barat berada di atas nilai varian. Hal ini disebabkan kondisi temperatur udara permukaan di sumatera Barat pada tahun 2004 lebih rendah dari temperatur udara permukaan rata-rata Sumatera Barat selama periode 1980 - 2017. Rendahnya nilai temperatur udara permukaan ini terjadi bersamaan dengan El Nino. 


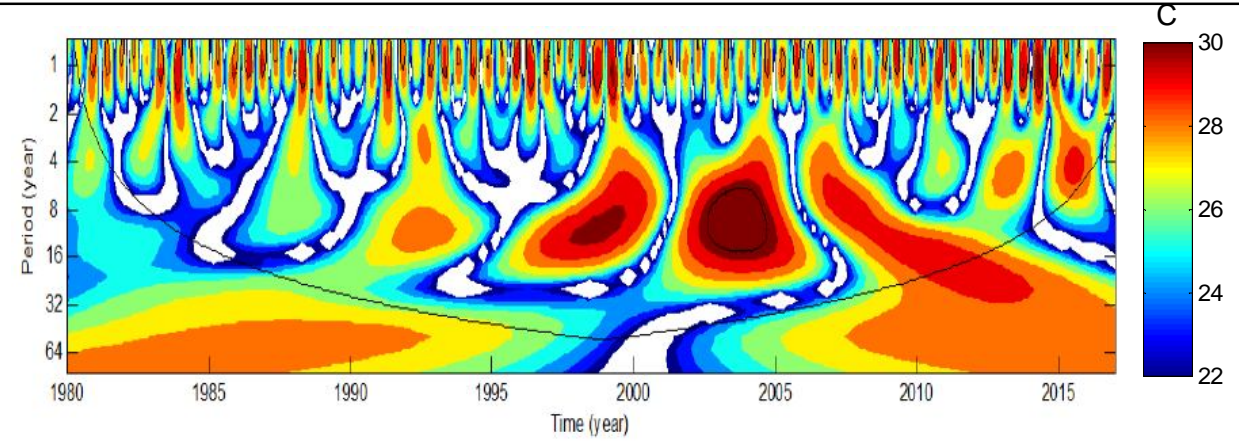

(a)

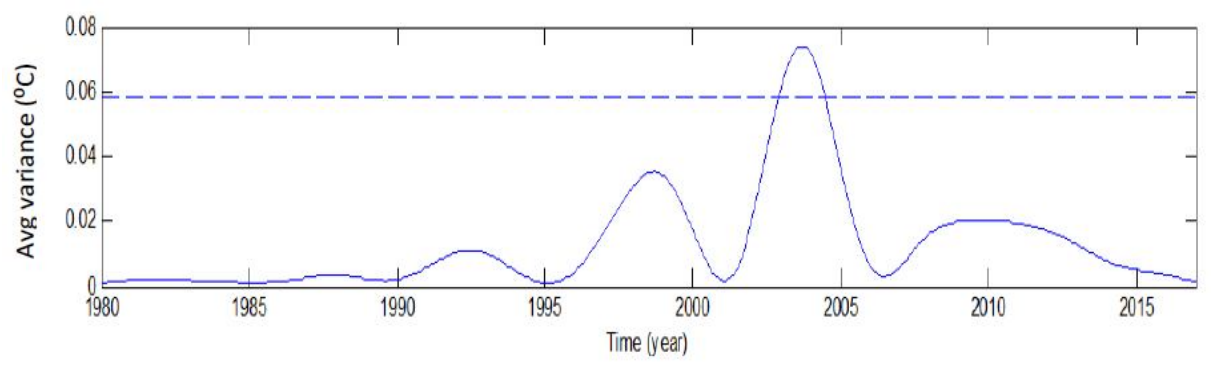

(b)

Gambar 6 Spektrum global wavelet osilasi temperatur (a) dan rata-rata varian temperatur (b) di Sumatera Barat selama 38 Tahun $(1980$ - 2017)

\section{KESIMPULAN}

Penelitian ini menunjukkan bahwa temperatur udara permukaan rata - rata di Sumatera Barat bervariasi antara satu daerah dengan daerah lainnya. Tren temperatur udara rata - rata di Sumatera Barat meningkat dengan laju peningkatan bervariasi antara $0,007-0,01^{\circ} \mathrm{C} /$ tahun . Selain itu tren temperatur udara maksimum dan minimum hariannya juga mengalami peningkatan berturut-turut $0,058^{\circ} \mathrm{C} /$ tahun dan $0,028^{\circ} \mathrm{C} /$ tahun di Kota Padang, $0,066^{\circ} \mathrm{C} /$ tahun dan $0,045^{\circ} \mathrm{C} /$ tahun di Kabupaten Padang Pariaman, serta $0,063^{\circ} \mathrm{C} /$ tahun dan $0,0332{ }^{\circ} \mathrm{C} /$ tahun di Kota Padang Panjang. Periode perulangan dominan temperatur udara permukaan di Sumatera Barat adalah 1 tahun (osilasi tahunan). Selain itu, juga terdapat osilasi 4 tahun dan 8 tahun yang menyatakan bahwa temperatur udara permukaan di wilayah pengamatan Sumatera Barat dipengaruhi oleh munson dan ENSO.

\section{DAFTAR PUSTAKA}

Dinas Kehutanan Sumatera Barat, 2014, Status Lingkungan Hidup Daerah Provinsi Sumatera Barat 2014, Bapedalda Provinsi Sumatera Barat.

Fadholi,Akhmad, Uji Perubahan Rat-rata Temperatur Udara dan Curah Hujan di Kota Pangkal Pinang, Jurnal Matematika, Sains, dan Teknologi, 14(1), 2013, Hal. 11- 25.

Hartmann, D.L., Klein T., Rusticucci, M., Alexander, L.V., Brönnimann, S., $\quad$ Charabi, Y., Dentener, F.J., Dlugokencky, E.J., Easterling, D.R., Kaplan, A., Soden, B.J.,

Thorne, P.W., Wild, M., Zhai, P.M., 2013. Observations: atmosphere and surface. In Climate Change 2013: The Physical Science Basis.Contribution of Working GroupI to the Fifth Assessment Report of the Intergovernmental Panel on Climate Change, Stocker, T.F., Qin, D., Plattner G.K., Tignor, M., Allen, S.K., Boschung, J., Nauels, A., Xia, Y., Bex, V., Midgley, P.M., Cambridge University Press: Cambridge, UK and New York, NY.

He, Y., Wu, Z., Liu, X., Deng, F., Analysis of surface air temperature variations and local urbanization effects on central Yunnan Plateau, SW China, Theoritical and Applied Climatology, 10( 107), Hal. 1130-1140.

IPCC, 2007, Climate Change 2007: The Physical Science Basis. Contribution of Working Group I to the Fourth Assessment Report of the Intergovernmental Panel on Climate Change Cambridge University Press, Cambridge, United Kingdom and NewYork, NY, USA. 
Jones, P.D., Lister, D.H., Osborn, T.J., Harpham, C., Salmon, M., Morice, P.C., Hemispheric and large-scale land-surface air temperature variations : an extensive revision and an update to 2010. Journal of Geophysical Research Atmospheres, 117(5), 2012, Hal. 127-139.

Martínez, M.D., Serra, C., Burgueño, A., Lana, X., Time trends of daily maximum and minimum temperatures in Catalonia (NE Spain) for the period 1975-2004. International Journal of Climatology, 30(5), 2010, Hal. 267-290.

Morán-Tejeda, E., Bazo, J., López-Moreno, J.I., Aguilar, E., Azorín-Molina, C., SanchezLorenzo, A., Martínez, R., Nieto, J.J., Mejía, R., Martín- Hernández,N., Vicente Serrano,S.M.,Climate trends and variability in Ecuador (1966-2011). International Journal of Climatology, 36(11), 2016, Hal. 3839- 3855.

Nalley,D., Adamowski, J., Khalil, B., Ozga-Zielinski, B., Trend Detection in Surface Aair Temperature in Ontario and Quebec, Canada during 1967 - 2006 Using The Discrete Wavelet Transform. Atmospheric Research, 11(1), 2013, Hal. 1-74.

Purwantara, Suhadi, Studi Temperatur Udara Terkini di Wilayah Jawa Tengah dan DIY, Geomedia, 1(13), 2015, Hal. 41-52.

Vicente-Serrano, S.M., Lopez-Moreno, J.I., Correa, K., Avalos, G., Bazo, J., $\quad$ AzorinMolina, C., Dominguez-Castro, F., Kenawy, A.E., Gimeno, L., Nieto, R., Recent changes in monthly surface air temperature over Peru, 1964- 2014, International Journal of Climatology, 10(1002), 2017, Hal. 1146 - 1163.

Yuggotomo, M., E., dan Ihwan, A., 2014, Pengaruh Fenomena El Niño Southern Oscillation dan Dipole Mode Terhadap Curah Hujan di Kabupaten Ketapang. Positron, 4(2), 2014, Hal. 35-39.

BMKG Repository, 2014, La Nino \& La Nina, Badan Meteorologi dan Geofisika, Indonesia, http://cews.bmkg.go.id., diakses Desember 2018. 